\title{
Liver manipulation during liver surgery in humans is associated with hepatocellular damage and hepatic inflammation.
}

Citation for published version (APA):

van den Broek, M. A., Shiri-Sverdlov, R., Schreurs, J. J., Bloemen, J. G., Bieghs, V., Rensen, S. S. M., Dejong, C. H. C., \& Olde Damink, S. (2013). Liver manipulation during liver surgery in humans is associated with hepatocellular damage and hepatic inflammation. Liver International, 33(4), 633-641. https://doi.org/10.1111/liv.12051

Document status and date:

Published: 01/01/2013

DOI:

10.1111/liv.12051

Document Version:

Publisher's PDF, also known as Version of record

Document license:

Taverne

Please check the document version of this publication:

- A submitted manuscript is the version of the article upon submission and before peer-review. There can be important differences between the submitted version and the official published version of record.

People interested in the research are advised to contact the author for the final version of the publication, or visit the DOI to the publisher's website.

- The final author version and the galley proof are versions of the publication after peer review.

- The final published version features the final layout of the paper including the volume, issue and page numbers.

Link to publication

\footnotetext{
General rights rights.

- You may freely distribute the URL identifying the publication in the public portal. please follow below link for the End User Agreement:

www.umlib.nl/taverne-license

Take down policy

If you believe that this document breaches copyright please contact us at:

repository@maastrichtuniversity.nl

providing details and we will investigate your claim.
}

Copyright and moral rights for the publications made accessible in the public portal are retained by the authors and/or other copyright owners and it is a condition of accessing publications that users recognise and abide by the legal requirements associated with these

- Users may download and print one copy of any publication from the public portal for the purpose of private study or research.

- You may not further distribute the material or use it for any profit-making activity or commercial gain

If the publication is distributed under the terms of Article 25fa of the Dutch Copyright Act, indicated by the "Taverne" license above, 


\title{
LIVER SURGERY
}

\section{Liver manipulation during liver surgery in humans is associated with hepatocellular damage and hepatic inflammation}

\author{
Maartje A. J. van den Broek ${ }^{1}$, Ronit Shiri-Sverdlov ${ }^{2}$, Joris J. W. Schreurs ${ }^{1}$, Johanne G. Bloemen ${ }^{1,3}$, Veerle Bieghs ${ }^{2}$, \\ Sander S. Rensen ${ }^{1,3}$, Cornelis H. C. Dejong ${ }^{1,3}$ and Steven W. M. Olde Damink ${ }^{1,3,4}$ \\ 1 Department of Surgery, Maastricht University Medical Centre, Maastricht, the Netherlands \\ 2 Department of Molecular Genetics, Maastricht University, Maastricht, the Netherlands \\ 3 Department of Surgery, Nutrition and Toxicology Research Institute Maastricht, Maastricht University, Maastricht, the Netherlands \\ 4 Department of HPB Surgery and Liver Transplantation, Royal Free Hospital, University College London, London, UK
}

\section{Keywords}

anterior approach - hepatocellular damage inflammatory response - liver mobilization liver surgery

\section{Abbreviations \\ ALAT, alanine aminotransferase; CD, cluster of differentiation; ICAM, intercellular adhesion molecule; IL, interleukin; L-FABP, liver fatty acid-binding protein; MPO, myeloperoxidase; PLF, post-resectional liver failure; PCR, polymerase chain reaction; POD, post-operative day; VCAM, vascular cell adhesion molecule. \\ Correspondence \\ Ms. Maartje AJ van den Broek, Department of Surgery, Maastricht University Medical Centre, P.O. Box 5800, 6202 AZ Maastricht, the Netherlands \\ Tel: +31433877489 \\ Fax: +31433875473 \\ e-mail: m.vandenbroek \\ @maastrichtuniversity.nl}

Received 28 October 2012

Accepted 3 November 2012

DOI:10.1111/liv.12051

Liver Int. 2013: 33: 633-641

\begin{abstract}
Background: Manipulation of the liver during liver surgery results in profound hepatocellular damage. Experimental data show that mobilizationinduced hepatocellular damage is related to hepatic inflammation. To date, information on this link in humans is lacking. As it is possible to modulate inflammation, it is clinically relevant to unravel this relationship. Aim: This observational study aimed to establish the association between liver mobilization and hepatic inflammation in humans. Methods: Consecutive patients requiring mobilization of the right hemi-liver during liver surgery were studied. Plasma samples and liver biopsies were collected prior to and directly after mobilization and after transection of the liver. Hepatocellular damage was assayed by liver fatty acid-binding protein (L-FABP) and aminotransferase levels. Hepatic inflammation was determined by (a) immunohistochemical identification of myeloperoxidase (MPO) and CD68- positive cells and (b) hepatic gene expression of inflammatory and cell adhesion molecules (IL-1 $\beta$, IL-6, IL-8, VCAM-1 and ICAM-1). Results: A total of 25 patients were included. L-FABP levels increased significantly during mobilization $(301 \pm 94 \mathrm{ng} / \mathrm{ml}$ to $1599 \pm 362 \mathrm{ng} / \mathrm{ml}, P=0.008)$, as did ALAT levels $(36 \pm 5 \mathrm{IU} / \mathrm{L}$ to $167 \pm 21 \mathrm{IU} / \mathrm{L}, P<0.001)$. A significant increase in MPO $(P=0.001)$ and $\operatorname{CD} 68(P=0.002)$ positive cells was noticed in the liver after mobilization. The number of MPO-positive cells correlated with the duration of mobilization (Pearson correlation $=0.505, P=0.033$ ). Hepatic gene expression of pro-inflammatory cytokines IL-1 $\beta$ and IL-6, chemo-attractant IL-8 and adhesion molecule ICAM-1 increased significantly during liver manipulation. Conclusions: Liver mobilization is associated with hepatocellular damage and liver inflammation, as shown by infiltration of inflammatory cells and upregulation of genes involved in acute inflammation.
\end{abstract}

Surgical resection is the ultimate treatment for a variety of benign and malignant liver tumours. During liver surgery, there is a delicate balance between the attempt to achieve surgery with curative intent and the necessity to leave adequate remnant liver volume to avoid post-resectional liver failure (PLF). Risk factors for the development of PLF may either be surgery- or patient-related (1).

With respect to surgery-related risk factors, excessive intra-operative blood loss is associated with adverse post-resectional outcomes (2). To limit blood loss during liver surgery, different surgical techniques have been introduced. One of these techniques is mobilization of the liver prior to transection. During mobilization, the liver is forcefully manipulated to dissect its ligaments and control direct venous branches to the inferior caval vein. Recent data deliver convincing evidence that mobilization of the liver in itself causes substantial hepatocellular injury (3-7). The highly sensitive liver cell damage markers liver fatty acid-binding protein (L-FABP), arginase-1, glutathione-s-transferase- $\alpha$ and cell-free circulating albumin-mRNA increased significantly during mobilization of the liver and did not increase thereafter during either inflow occlusion or transection (3-7). Of important notice, manipulationinduced liver cell damage negatively affected postoperative outcomes in patients undergoing liver surgery for hepatocellular carcinoma (7).

The pathogenesis of mobilization-induced liver damage has been studied in detail in a murine model of 
liver transplantation (8-10). In short, mobilization of the liver induced neuronal mediated disturbances in the hepatic microcirculation leading to both liver cell damage and hepatic inflammation. Activated Kupffer cells seemed to play a central role as modulation of their function largely prevented hepatocellular damage and improved experimental outcome (11). In man, it has been shown that systemic inflammation, reflected by plasma interleukin-6 (IL-6) levels, followed liver manipulation during surgery (3). However, the source of this systemic inflammatory response is yet unidentified in humans. Based on aforementioned experimental observations, hepatic inflammation might well be involved in the cascade of manipulation-induced liver cell damage and systemic inflammation.

Given the possibility to modulate the inflammatory response, identification of the link between manipulationinduced liver cell injury and inflammation in man could identify novel therapeutic strategies for its prevention. This study aimed to establish the association between liver mobilization, hepatocellular damage and hepatic inflammation in patients undergoing liver surgery.

\section{Patients and methods}

\section{Patients}

Consecutive patients scheduled to undergo liver surgery requiring full mobilization of the right hemi-liver at Maastricht University Medical Centre between October 2007 and June 2009 were included in this observational study. Exclusion criteria were (a) the presence of cirrhosis of the liver confirmed by pre-operative liver biopsy, (b) repeat liver surgery, (c) laparoscopic liver surgery, (d) use of anti-inflammatory drugs, (e) presence of renal failure (defined as serum creatinine $>137 \mu \mathrm{mol} / \mathrm{L}$ in males and $>104 \mu \mathrm{mol} / \mathrm{L}$ in females (12)), (f) performance of an extra-hepatic procedure, and (g) participation in another trial.

Resections were divided into major ( $\geq 3$ Couinaud segments) or minor ( $<3$ Couinaud segments or nonanatomical wedge resections) (13). All data were prospectively entered in a database and the clinical course of the participants was studied up until 90 days after discharge. The incidence rate of the liver surgery specific composite endpoint and its individual components (ascites, bile leakage, intra-abdominal haemorrhage, intra-abdominal abscess, PLF and operative mortality) was calculated (14). This study was approved by the Medical Ethics Committee of Maastricht University Medical Centre and all participating individuals gave written informed consent.

\section{Surgical procedure}

Patients routinely had two peripheral venous catheters and indwelling catheters in a jugular vein and radial artery. Immediately pre-operatively, all patients received a single intravenous dose of 2200-mg amoxicillin/clavulanic acid as antibiotic prophylaxis. Propofol and isoflurane were used as anaesthetics. Surgical procedures were commenced using a subcostal bilateral incision as described earlier (5). An Omni-Flex General Retractor System (Integra LifeSciences Corporation, Plainsboro, NJ, USA) was used to improve exposure. After dissection of the teres hepatis ligament, the procedure was continued with dissection of the falciform ligament and further mobilization of the right hemi-liver from the posterior abdominal wall. Thereafter, the liver was rotated anteriorly and to the left to dissect direct venous branches to the inferior caval vein. Full mobilization was reached when the caval vein was dissected free of all its attachments at the 12 o'clock anterior surface. Subsequently, an intra-operative ultrasound was performed, which directed the surgical strategy. A Cavitron Ultrasonic Surgical Aspirator (CUSA system 200 macrodissector, Cavitron Surgical Systems, Stamford, CT, USA) and Argon beam coagulation (Force GSU System, Valleylab, Boulder, CO, USA) were used for liver transection. Inflow occlusion was not routinely applied. If necessary, a complete or selective Pringle manoeuvre (with 15-min or 30-min ischaemic cycles) or ligation of the appropriate portal pedicle vessels was applied (5). During transection, central venous pressure was maintained below $5 \mathrm{mmHg}$. Post-operative care was provided according to an Enhanced Recovery After Liver Surgery programme (15).

\section{Blood and tissue sampling}

Before, during and after the operative procedure, arterial blood was drawn from the radial artery catheter according to a predetermined protocol at different time points (Fig. 1). Blood samples were transferred to prechilled EDTA tubes and subsequently centrifuged at $4{ }^{\circ} \mathrm{C}$ at $3500 \mathrm{~g}$ for $15 \mathrm{~min}$. Plasma was stored at $-80^{\circ} \mathrm{C}$ until batch analysis.

Liver wedge biopsies were taken using scissors at fixed time points during the procedure from segment 5 of the liver. The first liver wedge biopsy was obtained immediately after opening of the abdomen and before touching or manipulating the intestines or liver, the second biopsy was collected after full mobilization of the right hemiliver and before application of inflow occlusion or liver transection, and the third after liver transection. Defined $0.5 \times 0.5 \mathrm{~cm}$ fragments of liver tissue were cut, snapfrozen in liquid nitrogen and stored at $-80^{\circ} \mathrm{C}$. Fragments of the same size were immersed in Tissue-Tek optimal cutting temperature compound (Sakura Finetek Europe, Zoeterwoude, The Netherlands) and mounted on a piece of cork before they were frozen in prechilled isopentane on dry ice and stored at $-80^{\circ} \mathrm{C}$.

\section{Hepatocellular damage}

The extent of hepatocellular damage was assessed by plasma concentrations of L-FABP and aminotransferases. 


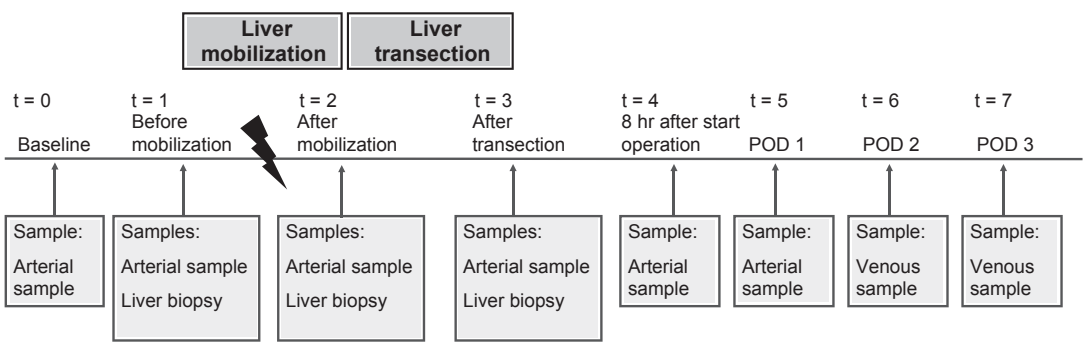

Fig. 1. Flowchart of blood and tissue collection. Legend: POD, post-operative day.

L-FABP is a sensitive marker for the detection of liver cell damage $(16,17)$. L-FABP levels were determined using a commercially available ELISA (Hycult Biotechnology, Uden, the Netherlands). According to the manufacturer's manual, L-FABP plasma levels in healthy individuals are approximately $12 \mathrm{ng} / \mathrm{ml}$. Alanine aminotransferase (ALAT) levels were assayed by the clinical chemistry laboratory of Maastricht University Medical Centre. The upper limit of normal was $35 \mathrm{IU} / \mathrm{L}$.

\section{Immunohistochemistry of the liver}

Tissue-Tek-embedded frozen liver biopsies were cut in $7-\mu \mathrm{m}$ sections, fixed in acetone for $10 \mathrm{~min}$ and subsequently blocked for endogenous peroxidase activity by incubation in $0.3 \% \mathrm{H}_{2} \mathrm{O}_{2}$ in PBS. Primary antibodies were applied for $1 \mathrm{~h}$ after blocking with $10 \%$ serum. The following primary antibodies were used: (i) rabbit anti-human myeloperoxidase (MPO) antiserum (dilution 1:1000; DakoCytomation) as marker for neutrophils and macrophages; (ii) anti-CD68 (clone Kp1, dilution 1:400; Dako, Glostrup, Denmark) specific for monocytes/macrophages; and (iii) anti-caspase-3-mediated cleavage generated neo-epitope of cytokeratin 18 (M30, dilution 1:50; Roche, Mannheim, Germany) specific for hepatocyte apoptosis, as described previously (18). Secondary antibodies consisted of horseradish peroxidase-labelled goat anti-rabbit IgG (1:500; Jackson immunoResearch, Suffolk, UK) for MPO staining. For CD68 and M30 staining, biotinylated rabbit antimouse IgG was applied as secondary antibody (1:300 and 1:500 dilution, respectively), and the StrepAB/HRP complex (DakoCytomation) was used for signal enhancement. Staining was visualized by DAB followed by haematoxylin for nuclear counterstaining. The stained slides were photographed at $200 \times$ magnification using a Nikon digital camera DXM1200 and ACT-1 v2.63 software from Nikon Corporation. Cells were counted in six randomly selected microscopical views, and cell numbers were noted as cells $/ \mathrm{mm}^{2}$ for MPO and M30 staining and as $0-3$ ordinal scale for CD68 staining. The number of CD68-positive cells was categorized as follows: 0 (none); 1 (few); 2 (moderate numbers); 3 (many). In addition, the morphology of CD68-positive cells was graded on a 1-3 scale as follows: 1 (normal appearance); 2 (moderate enlargement); 3 (substantial enlargement).

\section{Gene expression of inflammatory mediators in the liver}

Expression of genes encoding for inflammatory mediators and cell adhesion molecules was determined in liver biopsies taken at three time points during surgery (Fig. 1). Genes of interest included interleukin 1 beta (IL-1 $\beta$ ) and interleukin 6 (IL-6), both pro-inflammatory cytokines involved in macrophage activation, interleukin 8 (IL-8), a chemokine involved in recruitment of inflammatory cells, and vascular cell adhesion molecule (VCAM-1) and intercellular adhesion molecule (ICAM-1), important for adhesion and migration of inflammatory cells.

Hepatic gene expression was assessed by real-time quantitative polymerase chain reaction (PCR). Total RNA was isolated from snap-frozen liver samples using Tri-reagent (Sigma-Aldrich, St. Louis, USA). Reverse transcription was performed using the iScript cDNA synthesis kit (Bio-Rad, Hercules, USA). Real-time PCR was performed on a Bio-Rad MyIQ using IQ SYBR Green Supermix (Bio-rad, Hercules, USA). Primers for target genes were developed using Primer Express version 2.0 (Applied Biosystems, Foster City, USA). Sequences of the applied PCR primers are listed in Supplementary Material 1 . To standardize for cDNA concentration in the samples, the housekeeping gene cyclophylin A (peptidylprolyl isomerase A) was used. For calculations of the initial amount of mRNA present in the sample, the relative standard curve method was used.

\section{Statistical analysis}

Data are given as mean and standard error of the mean or median with range, depending on the nature of the data. Differences in hepatocellular damage markers, number of MPO and M30-positive cells, and hepatic gene expression between the three time points during liver surgery (before mobilization, after mobilization and after transection) were calculated using the paired sample $t$-test. For CD68 number and morphology, median values were compared using Wilcoxon's signed 
rank test. In addition, correlations between duration of mobilization, influx of inflammatory cells and hepatic gene expression were calculated. A $P$-value $<0.05$ was considered statistically significant. Statistical analysis was performed using the statistical package for the social sciences 20 (SPSS Inc., Chicago, Illinois, USA).

\section{Results}

\section{Patient flow}

Between October 2007 and July 2009, one-hundred and two patients were scheduled to undergo a partial hepatic resection. Of these, 25 patients fulfilled the inclusion criteria. Reasons for exclusion were as follows: presence of underlying liver disease confirmed by pre-operative liver biopsy $(n=4)$, repeat liver surgery $(n=6)$, laparoscopic liver surgery $(n=7)$, no informed consent $(n=9)$, participation in another trial $(n=6)$, no liver resection during surgery $(n=15)$, no formal mobilization of right hemi-liver $(n=24)$, and performance of an extra-hepatic procedure $(n=6)$.

\section{Patient characteristics}

Characteristics of the included patients are shown in Table 1. Liver surgery was performed because of benign hepatic disease in 1 and secondary hepatic malignancies in 24 patients, consisting of colorectal liver metastases in 23 and carcinoid metastases in 1 patient respectively. Major liver resections were performed in 17 and minor in 8 patients, with a median number of 4 resected segments (range 1-4). Mean operative time was $213 \pm 11 \mathrm{~min}$, of which $65 \pm 5 \mathrm{~min}$ were used for mobilization of the right hemi-liver and $94 \pm 8 \mathrm{~min}$ for transection of liver parenchyma. The extent of resection did not influence the duration of liver mobilization (70 $\pm 6 \mathrm{~min}$ for major resections versus $53 \pm 8 \mathrm{~min}$ for minor resections, $P=0.112$ ). During transection, a Pringle manoeuvre was applied in 15 patients (60\%). Mean cumulative ischaemia time in patients undergoing transection with a complete Pringle manoeuvre was $55 \pm 7$ min. For patients with a selective Pringle manoeuvre of the right hemi-liver, mean cumulative ischaemia time was $30 \pm 4 \mathrm{~min}$.

The incidence of the liver surgery specific composite endpoint was $16 \%$ ( 4 of 25 patients). The component accounting for this incidence was bile leakage in all four patients. The rates of PLF and operative mortality were zero.

\section{Liver cell damage markers increase significantly after liver} mobilization

To characterize liver cell damage secondary to liver manipulation, L-FABP and ALAT levels were measured. Mean arterial L-FABP levels increased significantly during mobilization of the right hemi-liver (from
Table 1. Patient characteristics $(n=25)$

\begin{tabular}{lc}
\hline Pre-operative characteristics & \\
Age (years) & $61(2)$ \\
Sex (male) & $17(68 \%)$ \\
BMI (kg/m²) & $26(1)$ \\
Primary disease & $1(4 \%)$ \\
Benign & $24(96 \%)$ \\
Malignant & \\
Pre-operative laboratory tests & $30(4)$ \\
ALAT (IU/L) & $13(1)$ \\
Bilirubin (total) ( $\mu$ mol/L) & $11(1)$ \\
Prothrombin time (sec) & $87(3)$ \\
Creatinine ( $\mu$ mol/L) & \\
Operative variables & \\
Type of resection & $12(48 \%)$ \\
Right hepatectomy & $4(16 \%)$ \\
Trisectionectomy & $9(36 \%)$ \\
Segmentectomy & $4(1-4)$ \\
Median number resected segments (range) & $213(11)$ \\
Duration of surgery (min) & $65(5)$ \\
Mobilization time (min) & $94(8)$ \\
Transection time (min) & $15(60 \%)$ \\
Pringle manoeuvre & $7(28 \%)$ \\
Selective Pringle & $8(32 \%)$ \\
Complete Pringle & $1002(167)$ \\
Total blood loss (ml) & \\
Post-operative outcome & $4(16 \%)$ \\
Liver surgery specific composite endpoint & \\
\hline
\end{tabular}

Numbers indicate mean (SEM) or absolute number (\%) unless otherwise indicated; ALAT, alanine aminotransferase; BMI, body mass index.

$301 \pm 94 \mathrm{ng} / \mathrm{ml} \quad$ to $\quad 1599 \pm 362 \mathrm{ng} / \mathrm{ml}, \quad P=0.008)$, and did not increase significantly thereafter $(2791 \pm 872$ $\mathrm{ng} / \mathrm{ml}, P=0.696$ vs after mobilization), as depicted in Fig. 2A. ALAT concentration also increased significantly during mobilization of the right hemi-liver (from $36 \pm 5 \mathrm{IU} / \mathrm{L}$ to $167 \pm 21 \mathrm{IU} / \mathrm{L}, P<0.001)$ and further increased during transection $(408 \pm 61 \mathrm{IU} / \mathrm{L}, P<0.001$ vs after mobilization, Fig. 2B). The increase in hepatocellular damage markers after mobilization did not relate to the extent of hepatic resection or the duration of mobilization (data not shown).

\section{Liver mobilization results in hepatocyte apoptosis}

Staining for M30 indicated that hepatocyte apoptosis tended to increase after mobilization $(P=0.09)$ and returned to baseline after transection (Fig. 3). There was a significant correlation between the duration of mobilization and the absolute increase in M30-positive cells (Pearson correlation $=0.507, P=0.027$ ).

\section{Liver mobilization increases the number of hepatic immune cells}

To study mobilization-mediated inflammation, inflammatory cells were identified in liver biopsies at three time points in 22 of the 25 included patients $(88 \%)$ by detection of MPO and CD68. Staining for MPO, 

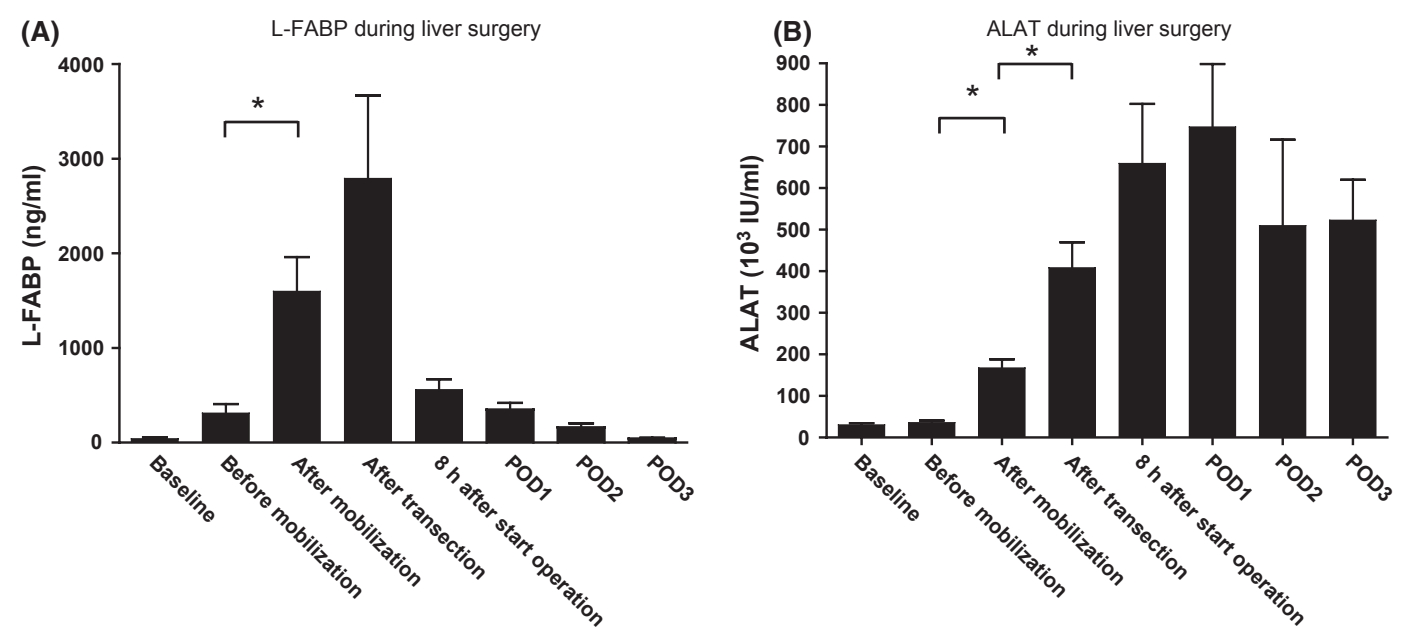

Fig. 2. $A$ and $B$. Course of hepatocellular damage markers L-FABP and ALAT during and after liver surgery. (A) L-FABP levels increased significantly during mobilization of the liver. L-FABP levels peaked at the end of surgery and decreased thereafter (mean and SEM). (B) ALAT levels increased during mobilization of the liver and continued to increase significantly thereafter, until reaching their peak at the first post-operative day (mean and SEM). Legend: *indicates $P<0.05$; L-FABP, liver fatty acid-binding protein; ALAT, alanine aminotransferase; POD, post-operative day.

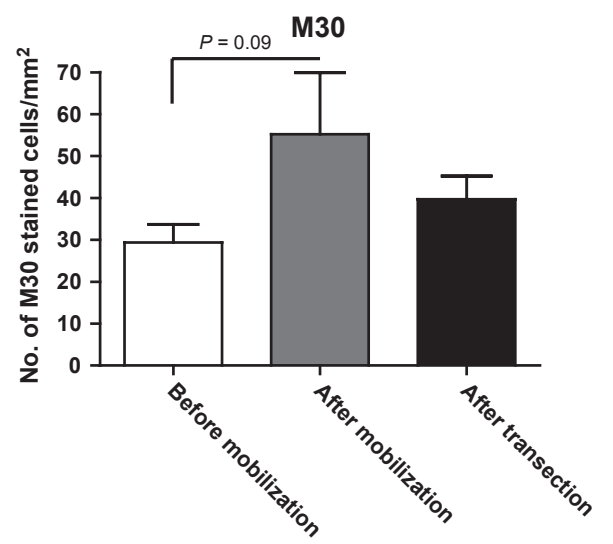

Fig. 3. Apoptosis of hepatocytes during liver surgery as evidenced by M30-staining. Liver mobilization resulted in a non-significant two-fold increase in M30-stained cells (mean and SEM).

a marker for neutrophils and macrophages, revealed a significant increase in absolute number of MPO-stained cells in liver tissue after mobilization $(P=0.001)$, which did not rise significantly during transection $(P=0.08)$ (Fig. 4A). There was a significant correlation between the absolute increase in MPO-positive cells after mobilization and the duration of mobilization (Pearson correlation $=0.505, P=0.033$ ).

Staining for CD68, a specific marker for macrophages, showed a small but significant increase in CD68positive cells after mobilization (median score 2 [1-2.5] before vs 2.5 [2-3] after mobilization, $P=0.002$ ) (Fig. 4B). These CD68-positive cells had a different morphology, characterized by enlargement and rounding after mobilization (median morphology score 1.5 [1-3] before vs $2[1-3]$ after mobilization, $P=0.003$ )
(Fig. 4C), suggesting that these cells represented monocytes that infiltrated the liver.

Liver mobilization induces hepatic expression of inflammatory genes

Enhanced expression of genes of pro-inflammatory cytokines, chemokines and adhesion molecules plays a significant role in promoting immune cell infiltration. In agreement with the histological findings, hepatic mRNA levels of IL-1 $\beta$, IL-6 and IL-8 (Fig. 5A-C) significantly increased after mobilization compared with baseline levels. Rise in expression ranged from 23 -fold for IL-1 $\beta, 65$-fold for IL-8 and 137-fold for IL-6. The expression of the chemokine IL-8 significantly correlated with the absolute increase in MPO-positive cells (Pearson correlation $=0.516, P=0.049$ ). After transection, the mRNA levels of IL-1 $\beta$, IL- 6 and IL- 8 further increased (Fig. 5A-C).

The expression of the cell adhesion molecule ICAM-1, but not VCAM-1, increased significantly after mobilization (Fig. 5D-E). The increase in ICAM-1 gene expression tended to correlate with the absolute increase in MPO-positive cells (Pearson correlation $=0.455$, $P=0.089$ ).

\section{Discussion}

This study was designed to establish the association among liver mobilization, hepatocellular damage and hepatic inflammation during liver surgery in humans. Our data corroborate earlier observations that liver mobilization induces profound liver cell damage, as evidenced by an early and significant rise in the hepatocellular damage markers L-FABP and ALAT. In addition, 
(A)

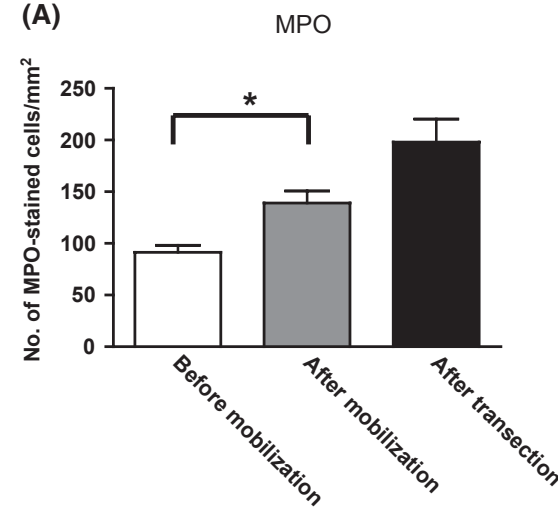

(B)

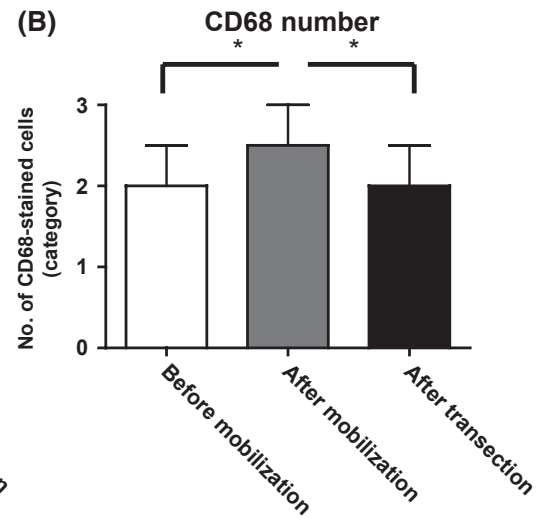

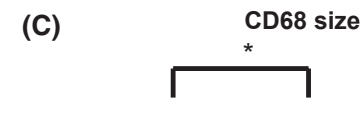

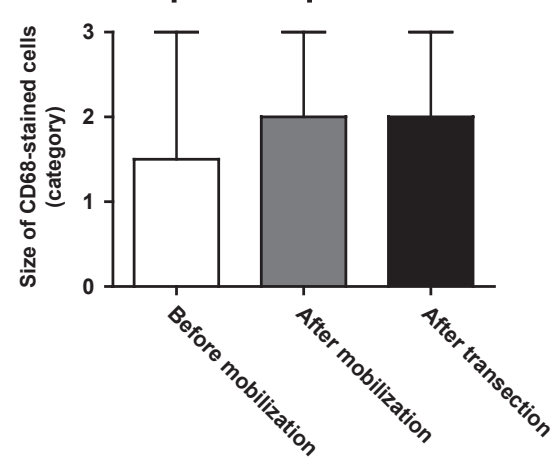

Fig. 4. A-C. Number of MPO and CD68-positive immune cells significantly increase during liver mobilization. (A) number of MPO-stained cells increased significantly during manipulation (mean and SEM). (B) CD68-staining revealed an increased number of CD68-positive cells in the liver after mobilization (median and range). (C) CD68-positive cells increased in size after mobilization of the liver (median and range). Legend: * indicates $P<0.05 ; \mathrm{MPO}$, myeloperoxidase; CD68, cluster of differentiation 68.

we present novel, human data indicating that liver mobilization is associated with liver cell apoptosis and hepatic inflammation, as shown by an increase in MPO and CD68-positive inflammatory cells and upregulation of mRNA of pro-inflammatory cytokines in the liver. The extent of apoptosis and increase in inflammatory cells was significantly related to the duration of mobilization.

Manipulation of the liver immediately led to hepatocellular damage. Levels of the damage markers L-FABP and ALAT were significantly increased after mobilization and there was a trend towards increased hepatocyte apoptosis, evidenced by M30-positive hepatocytes. We previously showed that the increase in systemic plasma levels of L-FABP and ALAT after liver mobilization solely resulted from hepatic release and not from the hepatotoxic effects of anaesthesia or surgical trauma of performing a laparotomy $(3,5)$. Interestingly, the course of ALAT levels showed a different pattern compared with L-FABP levels. ALAT levels peaked on the first post-operative day, at the same time and in the same range as reported by other groups $(19,20)$, whereas L-FABP levels reached their maximum values at the end of surgery and rapidly decreased thereafter. This might be a reflection of the fact that L-FABP is a more direct and sensitive marker for the detection of liver cell damage as compared with ALAT, because of the small molecular mass and short half-life of L-FABP $(16,17,21)$.

Hepatic inflammation has previously been recognized as an important element in the multifaceted process leading to manipulation-induced tissue injury in rodents $(8,22)$. In man, however, the relationship among liver manipulation, hepatocellular damage and hepatic inflammation was unknown. Here, we provide the first data in man showing that liver mobilization is accompanied by hepatocyte apoptosis and influx of inflammatory cells in hepatic tissue. Additional CD68 staining identified involvement of monocytes and macrophages. Our group previously showed that macrophages such as Kupffer cells are able to express MPO and speculated that this might reflect their pro-inflammatory status $(18,23)$. The present findings of enhanced hepatic expression of the typical pro-inflammatory macrophage markers IL-1 $\beta$ and IL- 6 are in line with this hypothesis.

It might be clinically relevant to prevent mobilization-induced liver cell damage, hepatocyte apoptosis 
(A)

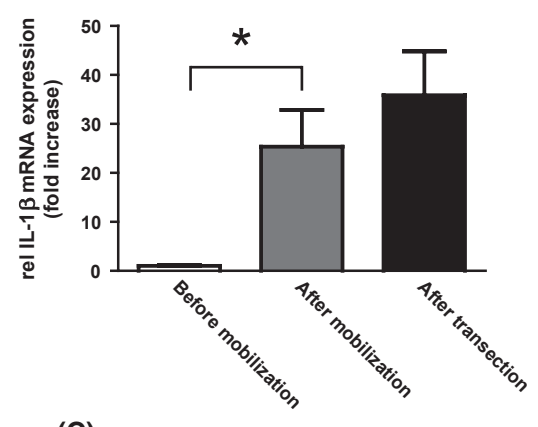

(C)
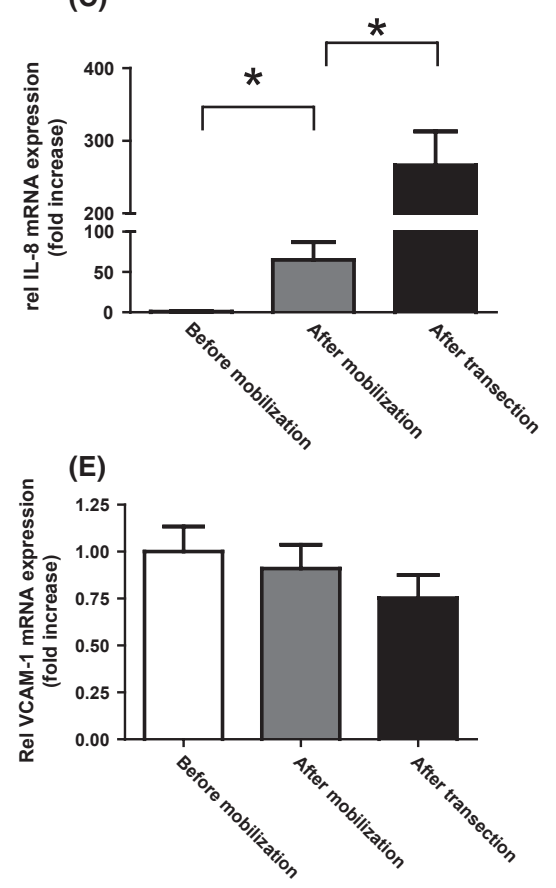

(B)

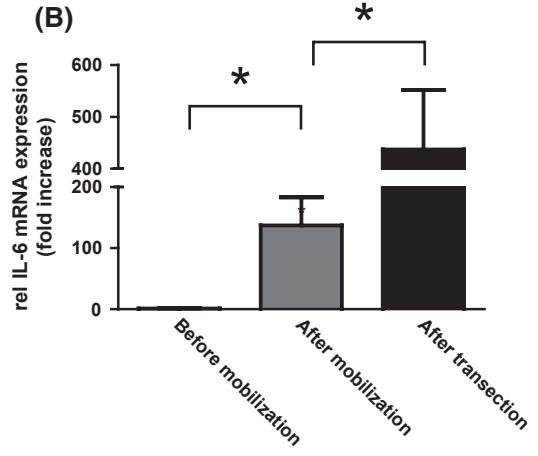

(D)

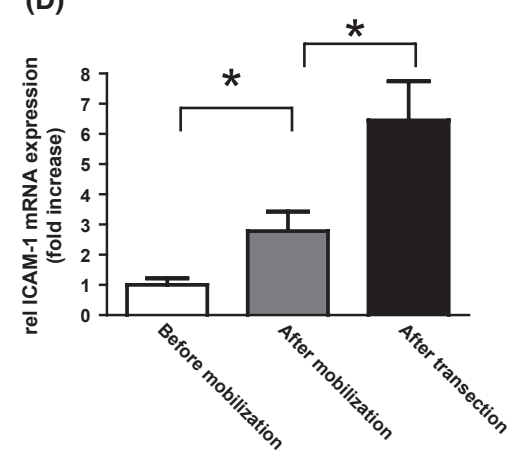

Fig. 5. A-E. Relative hepatic gene expression of inflammatory cytokines and cell adhesion molecules during liver surgery. (A-C) relative expression of IL-1 $\beta$, IL- 6 and IL-8 significantly increased during liver surgery (mean and SEM). (D-E) relative expression of ICAM-1 increased, whereas relative expression of VCAM-1 remained fairly constant (mean and SEM). Legend: IL, interleukin; VCAM, vascular cell adhesion molecule; ICAM, intercellular adhesion molecule; * indicates $P<0.05$.

and inflammation by either employment of alternative surgical techniques or modulation of inflammation. With respect to the latter, it remains unclear whether the presence and activation of inflammatory cells secondary to liver manipulation is beneficial or not. In general, unrestrained activation of inflammatory cells following trauma is believed to exacerbate damage, although initially intended to maintain homeostasis (24, 25). As human evidence on the clinical consequences of mobilization-induced liver inflammation is lacking to date, assumptions are solely based on results of animal studies. In animal models of liver manipulation-induced hepatocellular damage, the administration of gadolinium chloride, a Kupffer cell toxicant or glycine, which prevents Kupffer cell activation, led to decreased hepatocellular damage and improved survival after liver transplantation $(8,26)$. In other areas of research, modulation of inflammation secondary to manipulation has proven to be beneficial in terms of clinical outcomes in animals as well as humans (27-29). Intervention studies with anti-inflammatory drugs, aiming at a modulation of monocyte influx or macrophage activity, may be performed to elucidate whether a dampened inflammatory response would lead to less tissue injury and, more importantly, improved clinical outcome in patients undergoing liver surgery.

Alternative surgical techniques that require less manipulation of the liver are already available, such as laparoscopic liver resection or liver resection using the anterior approach $(30,31)$. Laparoscopy might be advantageous, although several reports show an unfavourable effect of the pneumoperitoneum on hepatic microcirculation (32, 
33). This is undesirable as animal study data suggest that microcirculatory failure mediates manipulation-induced liver cell damage (8). Liver resection using the anterior approach involves initial completion of parenchymal transection without mobilization of the right hemi-liver $(30,34)$. Advantages include minimal interruption of hepatic circulation during surgery, improved liver function and reduced risk of spilling viable cancer cells into the circulation, at the cost of an enhanced risk of bleeding (30). Indeed, Liu and coworkers showed reduced cell-free circulating albumin-mRNA levels, as a marker of circulating liver cells, and a lower incidence of PLF in patients undergoing liver resection using the anterior approach compared with the conventional approach (7). Comparison of hepatocellular damage, hepatic inflammation and clinical outcomes between patients undergoing liver surgery using the conventional approach vs the anterior approach is warranted.

The trigger for immune activation in mobilizationinduced liver damage in man remains to be identified. Oxidative stress-related danger signals, resulting from microcirculatory failure, might well be involved as triggers of local inflammation (11). Livers with reduced anti-oxidant capacity and pre-existent microvascular damage, such as livers suffering from chemotherapyassociated hepatotoxicity, may therefore be at additional risk $(35,36)$. Moreover, the relationship among mobilization-induced hepatocellular damage, hepatic inflammation and clinical outcome remains to be established in a trial using larger patient groups (37).

Taken together, the results of this study provide evidence of an association among liver mobilization, hepatocellular damage and hepatic inflammation in man, in line with previous results from animal studies. They form the basis for the development of novel therapies to prevent mobilization-induced damage early during liver surgery, such as the administration of immune-modulating drugs or adoption of alternative surgical techniques.

\section{Acknowledgements}

The authors thank VL Nguyen, MD, and SAWG Dello, $\mathrm{MD}$, for their help during sample collection. They also acknowledge $\mathrm{MH}$ Bemelmans, MD, PhD, WA Buurman, $\mathrm{PhD}$, and RM van Dam, MD, all from the Department of Surgery, Maastricht University Medical Centre, and $\mathrm{T}$ Hendrikx, $\mathrm{PhD}$, and $\mathrm{P}$ van Gorp, both from the department of Molecular Genetics, Maastricht University, for their valuable input during study design, sample analysis and interpretation of data.

Conflict Of Interest: Nothing to declare.

\section{References}

1. van den Broek MA, Olde Damink SW, Dejong CH, et al. Liver failure after partial hepatic resection: definition, pathophysiology, risk factors and treatment. Liver Int 2008; 28: 767-780.
2. Kooby DA, Stockman J, Ben-Porat L, et al. Influence of transfusions on perioperative and long-term outcome in patients following hepatic resection for colorectal metastases. Ann Surg 2003; 237: 860-869.

3. van de Poll MC, Derikx JP, Buurman WA, et al. Liver manipulation causes hepatocyte injury and precedes systemic inflammation in patients undergoing liver resection. World J Surg 2007; 31: 2033-2038.

4. Chouker A, Martignoni A, Schauer RJ, et al. Alpha-gluthathione S-transferase as an early marker of hepatic ischemia/reperfusion injury after liver resection. World J Surg 2005; 29: 528-534.

5. van den Broek MA, Bloemen JG, Dello SA, et al. Randomized controlled trial analyzing the effect of 15 or $30 \mathrm{~min}$ intermittent Pringle maneuver on hepatocellular damage during liver surgery. J Hepatol 2011; 55: 337-345.

6. van de Poll MC, Hanssen SJ, Berbee M, et al. Elevated plasma arginase-1 does not affect plasma arginine in patients undergoing liver resection. Clin Sci (Lond) 2008; 114: 231-241.

7. Liu CL, Fan ST, Cheung ST, et al. Anterior approach versus conventional approach right hepatic resection for large hepatocellular carcinoma: a prospective randomized controlled study. Ann Surg 2006; 244: 194-203.

8. Schemmer P, Schoonhoven R, Swenberg JA, Bunzendahl H, Thurman RG. Gentle in situ liver manipulation during organ harvest decreases survival after rat liver transplantation: role of Kupffer cells. Transplantation 1998; 65: 1015-1020.

9. Schemmer P, Bunzendahl H, Raleigh JA, Thurman RG. Graft survival is improved by hepatic denervation before organ harvesting. Transplantation 1999; 67: 1301-1307.

10. Schemmer P, Enomoto N, Bradford BU, et al. Autonomic nervous system and gut-derived endotoxin: involvement in activation of Kupffer cells after in situ organ manipulation. World J Surg 2001; 25: 399-406.

11. Schemmer P, Connor HD, Arteel GE, et al. Reperfusion injury in livers due to gentle in situ organ manipulation during harvest involves hypoxia and free radicals. J Pharmacol Exp Ther 1999; 290: 235-240.

12. Couchoud C, Pozet N, Labeeuw M, Pouteil-Noble C. Screening early renal failure: cut-off values for serum creatinine as an indicator of renal impairment. Kidney Int 1999; 55: 1878-1884.

13. Strasberg SM. Nomenclature of hepatic anatomy and resections: a review of the Brisbane 2000 system. $J$ Hepatobiliary Pancreat Surg 2005; 12: 351-355.

14. van den Broek MA, van Dam RM, van Breukelen GJ, et al. Development of a composite endpoint for randomized controlled trials in liver surgery. Br J Surg 2011; 98: 1138-1145.

15. van Dam RM, Hendry PO, Coolsen MM, et al. Initial experience with a multimodal enhanced recovery programme in patients undergoing liver resection. Br J Surg 2008; 95: 969-975.

16. Pelsers MM, Morovat A, Alexander GJ, et al. Liver fatty acid-binding protein as a sensitive serum marker of acute hepatocellular damage in liver transplant recipients. Clin Chem 2002; 48: 2055-2057.

17. Glatz JF, van der Vusse GJ. Cellular fatty acid-binding proteins: their function and physiological significance. Prog Lipid Res 1996; 35: 243-282.

18. Rensen SS, Slaats Y, Nijhuis J, et al. Increased hepatic myeloperoxidase activity in obese subjects with nonalcoholic steatohepatitis. Am J Pathol 2009; 175: 1473-1482. 
19. Scatton O, Zalinski S, Jegou D, et al. Randomized clinical trial of ischaemic preconditioning in major liver resection with intermittent Pringle manoeuvre. Br J Surg 2011; 98: 1236-1243.

20. Petrowsky H, McCormack L, Trujillo M, et al. A prospective, randomized, controlled trial comparing intermittent portal triad clamping versus ischemic preconditioning with continuous clamping for major liver resection. Ann Surg 2006; 244: 921-928.

21. Sugiyama $\mathrm{Y}$, Ishizaki $\mathrm{Y}$, Imamura $\mathrm{H}$, et al. Effects of intermittent Pringle's manoeuvre on cirrhotic compared with normal liver. Br J Surg 2010; 97: 1062-1069.

22. de Jonge WJ, The FO, van der Coelen D, et al. Mast cell degranulation during abdominal surgery initiates postoperative ileus in mice. Gastroenterology 2004; 127: 535545.

23. Mantovani A, Sica A, Locati M. New vistas on macrophage differentiation and activation. Eur J Immunol 2007; 37: 14 $-16$.

24. Ramaiah SK, Jaeschke H. Role of neutrophils in the pathogenesis of acute inflammatory liver injury. Toxicol Pathol 2007; 35: 757-766.

25. Nathan C. Points of control in inflammation. Nature 2002; 420: 846-852.

26. Schemmer P, Schoonhoven R, Swenberg JA, et al. Gentle organ manipulation during harvest as a key determinant of survival of fatty livers after transplantation in the rat. Transpl Int 1999; 12: 351-359.

27. The FO, Bennink RJ, Ankum WM, et al. Intestinal handling-induced mast cell activation and inflammation in human postoperative ileus. Gut 2008; 57: 33-40.

28. The FO, Buist MR, Lei A, et al. The role of mast cell stabilization in treatment of postoperative ileus: a pilot study. Am J Gastroenterol 2009; 104: 2257-2266.

29. The FO, de Jonge WJ, Bennink RJ, van den Wijngaard RM, Boeckxstaens GE. The ICAM-1 antisense oligonucleotide ISIS-3082 prevents the development of postoperative ileus in mice. Br J Pharmacol 2005; 146: 252-258.
30. Lai EC, Fan ST, Lo CM, Chu KM, Liu C. Anterior approach for difficult major right hepatectomy. World $J$ Surg 1996; 20: 314-318.

31. Fan ST. Protection of the liver during partial hepatectomy. Hepatobiliary Pancreat Dis Int 2004; 3: 490-494.

32. Schemmer P, Barro-Bejarano M, Mehrabi A, et al. Laparoscopic organ retrieval for living donor liver transplantation does not prevent graft injury. Transplant Proc 2005; 37: $1625-1627$.

33. Nsadi B, Gilson N, Pire E, et al. Consequences of pneumoperitoneum on liver ischemia during laparoscopic portal triad clamping in a swine model. J Surg Res 2011; 166: e35-e43.

34. Belghiti J, Guevara OA, Noun R, Saldinger PF, Kianmanesh R. Liver hanging maneuver: a safe approach to right hepatectomy without liver mobilization. J Am Coll Surg 2001; 193: 109-111.

35. DeLeve LD, Wang X, Kanel GC, et al. Decreased hepatic nitric oxide production contributes to the development of rat sinusoidal obstruction syndrome. Hepatology 2003; 38: 900-908.

36. Mehrabi A, Golling M, Busch C, et al. Experimental monitoring of hepatic glucose, lactate, and glutamate metabolism by microdialysis during surgical preparation of the liver hilus. J Surg Res 2002; 105: 128-135.

37. van den Broek MA, van Dam RM, Malago M, et al. Feasibility of randomized controlled trials in liver surgery using surgery-related mortality or morbidity as endpoint. $\mathrm{BrJ}$ Surg 2009; 96: 1005-1014.

\section{Supporting Information}

Additional Supporting Information may be found in the online version of this article:

Table S1. Primers used for quantitative polymerase chain reaction. 